\title{
Beyond Testing: Social and Psychological Considerations in Recruiting and Retaining Gifted Black Students
}

\author{
Donna Y. Ford \\ Gilman W. Whiting \\ Vanderbilt University
}

For more than a half century, concerns have existed about the persistent underrepresentation of African American students in gifted education and Advanced Placement classes. Various recommendations to reverse underrepresentation have been proposed, with the majority focusing on testing and assessment instruments. Nonetheless, progress has been inadequate as underrepresentation persists at high levels nationally, especially among Black males. Clearly, we must continue to find more effective tests and instruments, but we cannot stop there. In this article, we propose that, in the process of focusing on more effective ways to recruit and retain African American students, greater attention must be given to social and psychological factors, namely peer pressures and racial identity. Equally important, we must consider gender- the differential experiences of Black males and females. The discussion of these issues is followed by recommendations for change for educators.

Gifted education proponents contend that gifted students have exceptional or special needs, as do students receiving special education services. Without appropriate services-services designed to meet needs - gifts and talents may not be nurtured and may, ultimately, be lost. Accordingly, Congress passed legislation (i.e., the Javits Act of 1988, reauthorized in 1994) that recognizes the loss of gifts and talents specifically among low socioeconomic status (SES) students and culturally and linguistically diverse (CLD) students when not identified as gifted. The overarching goal of the act is to support efforts to identify and serve CLD students and low-SES students.

Despite such initiatives as the Javits Act and associated grants, the demographics of gifted education have been resistant to changegifted education is as racially and economically homogeneous today as

Donna Y. Ford is Professor of Education and Human Development at Vanderbilt University. Gilman W. Whiting is an assistant professor of African American and Diaspora studies and the Director of Undergraduate Studies in the African American and Diaspora Studies Program at Vanderbilt University. Journal for the Education of the Gifted. Vol. 34, No. 1, 2010, pp. 131-155. Copyright (C2010 Prufrock Press Inc., http://www.prufrock.com 
it was a half century ago (see Ford, 1998; Ford, Grantham, \& Whiting, 2008a). In various reports, the U.S. Department of Education has reported the consistent underidentification of African American, Latino, and American Indian students as gifted and, likewise, they are poorly represented in Advanced Placement (AP) classrooms (College Board, 2008). In both programs, underrepresentation is at least $50 \%$-although they make up $17 \%$ of the total population in public schools, African American students are only approximately $8 \%$ of the population in gifted education. This underrepresentation is well beyond statistical chance and above the Office for Civil Rights' 20\% discrepancy formula stipulation (see Ford \& Frazier Trotman, 2001). In this discussion, two caveats are in order: First, it should be noted that underrepresentation is greater for African American ${ }^{1}$ students than for other CLD groups; thus, African American students have been discussed and studied more than any other diverse group; and second, it should be noted that Black males are more underrepresented in gifted education than all student groups (U.S. Department of Education, 2006).

Borrowing from the literature in higher education, Ford (1994) proposed that the representation of African American (and other CLD) students can only improve when educational professionals focus on the twin and inseparable goals of increasing recruitment and retention. More directly, she urged educators to follow concepts, models, strategies, and efforts that exist in higher education to resolve underrepresentation problems. Recommendations were that educators must: (a) find culturally sensitive instruments, strategies, policies, and procedures to effectively recruit African American students; (b) find more effective and inclusive ways of retaining these students in gifted programs once recruited; and (c) collect data on gatekeeping factors in both the recruitment and retention of Black males and females in gifted education. She argued that underrepresentation must be examined in a comprehensive way so that initiatives could be specific and direct.

The majority of research and scholarship suggests that poor test performance is the primary reason African Americans are underrepresented in gifted education. Although we concur that tests play a 
central role, we also argue that to attribute underrepresentation extensively or exclusively to recruitment - tests and instruments - paints an inaccurate, distorted picture of the problem; that is, recruiting (vis à vis finding the right test) is only half of the underrepresentation problem. Ford (2004) reported that retention is often neglected when considering underrepresentation. This inattention to retaining Black students in gifted programs contributes to continued underrepresentation. Essentially, both recruitment and retention are much more comprehensive and complicated than simply finding the "right" test or instrument. Rather, we must consider quality of life in gifted classrooms-students' sense of belonging, relationships with peers and educators, academic support, expectations of self and others, and academic identity and self-perceptions (Harmon, 2002; Louie, 2005).

This article was not written to rehash concerns or debates about testing and assessment of gifted Black and other minority students. Instead, we have elected to focus on other issues that might move the field forward relative to effectively addressing underrepresentation. Stated another way, although the majority of publications and discussions focus on recruitment issues, namely finding fault with tests and instruments, we believe this focus detracts from our recognizing and attending to other fundamental barriers. In this article, we go beyond testing and assessment to address social and psychological considerations that impact underrepresentation. Specifically, we focus on peer pressures and racial identity, setting forth the proposition that recruitment and retention will be more effective when these areas are considered and addressed. We also give attention to gender considerations.

Elsewhere, we have contended that a significant representation barrier is the choice that African American students and their families make regarding participation in gifted education classes. Some African American students and their families have chosen to not participate in gifted programs and AP classes because of social-emotional and psychological concerns. Specifically, African American students may choose not to be in gifted programs and AP classes due to: negative peer pressures and concerns about being isolated from their African American peers (Ford, 1992, 1996; Fordham, 1988, 1991, 1996; Fordham \& Ogbu, 1986) and concerns about being alienated from and rejected by White students in such classes (Ford, 1994, 1996). In the first example, African American students may 
underachieve if accused of "acting White" by African American peers (Ford et al., 2008a, 2008b). Academically successful Black males and females complain about negative peer pressures because of their high grades, participation in gifted programs, speaking Standard English, and other conditions. It is this phenomenon-African American students accusing other African American students of acting Whitethat informs the remainder of this article. We propose that Black students who do not have a positive or engaged racial identity are more likely to succumb to negative peer pressures than others, as evidenced by underachievement and underrepresentation in gifted education. We also posit that Black males and females may cope differently with such pressures. Although this article focuses most on peer pressures from Black students, we are not denying that Blacks also face peer pressures from White students. African Americans in predominantly White gifted classes may feel alienated from and rejected by White classmates. This, too, can take its toll on the social, emotional, and psychological well-being of gifted Black students (see Moore, Ford, \& Milner, 2005).

\section{Social Issues: Peer Pressures and Accusations of Acting White}

It seems common practice for high-achieving students and for gifted students to confront negative peer pressures. A survey conducted by Brown and Steinberg (1990) of 8,000 high school students found that fewer than $10 \%$ of the high achievers were willing to be identified as part of the "brain" crowd, and students often withdrew from debate, computer clubs, and honors classes to avoid being labeled a "geek" or "nerd." The percentage was even lower for females than for males. Worth noting is that none of the high-achieving African Americans surveyed in the Brown and Steinberg study were willing to be considered part of the "brain" crowd.

For decades, there has been ongoing debate on the existence of acting White and its effect on African American students' motivation and achievement or performance. Acting White describes a set of social interactions in which Black students ridicule other Black students for investing in behaviors deemed characteristic of Whites 
(e.g., speaking standard English, raising a hand in class, or making good grades; Fryer \& Torelli, 2006).

McArdle and Young (1970) appear to be the first to have studied the acting White phenomenon. However, as Fryer and Torelli (2006) asserted and we concur, Fordham and Ogbu (1986) set the stage for increased research with their analysis of "Capital High," a predominantly Black high school in a low-income area of Washington, DC. Fordham and Ogbu argued for the existence of an oppositional culture among Black youth that eschews behaviors traditionally seen as the prerogative of Whites. Academically successful Black students expressed concerns about other Blacks teasing and degrading them for investing in education and dressing and speaking like White students. Some successful students went so far as to camouflage their achievements or stop achieving altogether to gain social acceptance and/or to decrease peer pressures. Many elementary school gifted Black students surveyed by Ford $(1994,1996)$ indicated that they often succumbed to negative peer pressures and that acting White was a painful accusation.

In a more recent study, Ford et al. (2008b) surveyed 166 African American students (grades 5-12) identified as gifted regarding the peer pressures they experience specifically related to accusations of acting White and acting Black. Comparisons were made across gender, grade level, and school performance (i.e., grade point average). Regardless of these variables, the sample was rather homogeneous in their responses and experiences. More than $80 \%$ had heard of acting White and acting Black, and most had been accused of acting White. The majority of students equated acting White with: (a) being intelligent; (b) speaking Standard English; (c) being a high achiever and caring about school; and (d) having mainly White friends. The opposite or reverse was found for their perceptions of acting Black: (a) being unintelligent; (b) speaking non-Standard English; (c) showing disinterest in school and learning; low achievement; (d) being thuggish and having "bad" behaviors and attitudes; and (e) showing a preference for hip-hop culture in dress and music.

Much speculation exists, followed by a few theories and research, about how peer pressures affect Black students' behaviors and achievement. Although it would be foolish to believe that all students respond to peer pressures, including charges of acting White, in the same way, 
it would be equally unwise to ignore that some students are negatively affected. Thus, educators working with gifted Black students must not discount the possibility that peer pressures contribute to underrepresentation. Relative to recruitment, if African American students feel forced to hide their intelligence by not doing their work or acting up in school, teachers and other educators may not see their strengths, contributing to underreferrals to gifted education (Ford et al., 2008b). Likewise, relative to retention, gifted Black students may get lower scores on purpose, and refuse to participate in gifted and AP classes in order to fit in. When students receive lower grades and send messages of "I don't want to be here," teachers (and parents) may remove Black students from such classes and programs.

\section{Gender Considerations}

When data on gifted education representation is disaggregated by race and gender, Black males are the most underrepresented group (U.S. Department of Education, 2006). African American males are greatly disenfranchised in educational settings and society at large. In the context of education, they have incredibly high dropout rates, low college attendance rates, high suspension and expulsion rates, low test scores, and are overrepresented in special education. Socially, they have the highest incarceration, underemployment, and unemployment rates. Relatively speaking, no other male group is as marginalized, stereotyped, and feared (Whiting, in press). As Upchurch (1997) lamented, Black males are frequently "convicted in the womb."

Several scholars, among them Grantham, Whiting, Hébert, and Bonner, have written considerably on the plight of not just African American males in general, but gifted African American males in particular. Despite being gifted, these males continue to face barriers in school settings, including their underrepresentation in gifted education and AP classes. Thus, their scholarship and perspectives, much needed and long overdue, have collectively been a clarion call to rectify this situation.

What additional barriers face Black males as they endeavor to achieve? Perhaps the most significant challenge is that of overcoming negative images presented constantly, and virtually unchallenged, in the media. Seldom do high-achieving, educationally engaged African 
American males get attention. Instead, viewers and readers are bombarded with images of crime, violence, drugs, sexual exploitation, and educational disdain. In multiple ways, Black males are dissuaded from seeing themselves as scholars (Whiting, 2006a) and, instead, encouraged to be athletes and entertainers. Luftig and Nichols (1989) also found evidence that gifted boys camouflaged or masked their giftedness by using humor or becoming class clowns. How are educators to see potential and/or giftedness in this group when such negative images are constant and polemic?

Not only do adults come to internalize pessimistic images of African American males, too many of these students learn to believe, emulate, and even reinforce the images imposed upon them (Grantham, 2004a, 2004b; Whiting, in press). Ford and Harris (1996) and Ford (1996) studied gender differences between gifted Black males and females in grades 4-6; findings indicated that gifted Black males had lower grades, exerted less effort in school, were more interested in sports and being popular or socially accepted, and were more likely to succumb to accusations of acting White than Black females. Similar results have been found by Grantham, Hébert, and Bonner.

\section{Psychological Issues: Racial Identity Development}

Although much research has explored the relationship between selfconcept and achievement, and between self-esteem and achievement, Ford (1996) argued that racially different populations have been shortchanged, because this scholarship has neglected to include or consider racial identity in the context of self-concept, self-esteem, and overall self-perception.

Due to space limitations, the psychological needs of gifted students in general are not discussed here. Rather, we address literature related to Black students, paying particular attention to their development as racial beings. Within this discussion, we rely extensively on the most widely researched theory of racial identity development (Cross, 1971, 1995; Cross \& Vandiver, 2001) as the groundwork of our discussion. Using this theory, we draw implications from research and conceptual perspectives on African American students in general to gifted African American students. The discussion of peer pressure relative to acting 
White accusations is incomplete without attention to racial identity. In the next section, we present one theory of Black racial identity and then apply this work to gifted African American students.

Attention to racial identity among African American students dates back to the early work of Clark and Clark (1940) who used Black and White dolls to examine the extent to which African American preschoolers recognized themselves as racial beings, and how they felt about being African American or different from Whites. The findings, which played a central role in the 1954 Brown v. Board of Education case, indicated that most of the preschoolers showed a preference for White dolls; most equated "good" and "pretty" with the White dolls, and "bad" and "ugly" with the Black dolls. Equally troubling, most of these young children thought they looked like the White dolls. Since then, numerous studies have replicated and/or examined some aspect of racial identity with African American adults and children. These studies often conclude that Blacks are more likely than White students to encounter barriers to healthy or positive racial identity development (e.g., Helms, 1985; Parham, 1989; Parham \& Helms, 1985; Smith, 1989; Spencer \& Markstrom-Adams, 1990).

Racial identity is the extent to which culturally diverse individuals are aware of, understand, and value their racial features, background, and heritage. For African Americans, answers to the "who am I?" question are likely to include both their person identity and social identity, which include views of oneself as a Black person in America. That is, racial identity includes a sense of what it means to hold dual membership in the U.S. - to be American and of African heritage.

Research on Black racial identity is often grounded in the premise that Black identity is related to feelings of pride, competence, and selfefficacy (Phinney, 1990), along with feeling connect to, engaged with, and an affinity to the Black community (Feagin \& Sikes, 1994). The literature has focused primarily on a sense of connectedness or common destiny, a positive sense of heritage and history, and an awareness of racism and negative stereotyping (Allen, Dawson, \& Brown, 1989; Oyserman, Gant, \& Ager, 1995).

As discussed below, Whiting (2006a, 2006b); Ford, Harris, and Schuerger (1993); Ford et al. (2008a, 2008b); Smith (1989); and Exum and Colangelo (1981) have proposed that, for African American students, racial identity has a significant impact on achievement, 
motivation, and attitudes toward academic achievement. That is, in the earlier stages or types of racial identity development, African American youth may deliberately underachieve and choose not to participate in gifted programs and AP classes to avoid peer pressures and accusations that they are "acting White" and/or to avoid rejection by White peers, or they may hide or downplay their abilities in order to be accepted socially by their same-raced peers (Ford et al., 2008a, 2008b; Fordham, 1988, 1991; Fordham \& Ogbu, 1986; Ogbu, 2003; Ogbu \& Simmons, 1998).

\section{Nigrescence Theory: One Theory of Black Racial Identity}

The most studied theory of racial identity was introduced by Cross in 1971, in which he outlined the stages of individual Black consciousness development associated with involvement in the Black Power Movement of the late 1960s (Cross \& Vandiver, 2001, p. 371). Since then, the theory has undergone two revisions (1995 and 2001). In the most recently revised model, entitled nigrescence theory, Cross and Vandiver (2001) distinguished between personal identity (PI) and social identity, also called reference group orientation (RGO), and clarified when to use the model developmentally and, thus, distinguished between stages and types of racial identities.

Nigrescence theory now rests on the assumption that the self-concept has two components-a general personality or personal identity component and a reference group orientation or social identity component (Cross \& Vandiver, 2001, p. 372). In the theory, personal identity (PI) plays a minor role in the definition of Black identity, with social identity (RGO) playing the key role. PI refers to one's personality (e.g., shy, quiet, aggressive, outgoing, mathematically inclined), while RGO helps the individual to make sense of him- or herself as a social being.

When nigrescence theory focuses on the outcomes of differing socialization experiences, the identity outcomes are called racial-reference group orientations or identity statuses rather than stages (Cross \& Vandiver, 2001, p. 377). However, when the focus is on social identity change in the context of an adult identity conversion, the identity types are called stages (p. 378). The theory presents three major exemplars (i.e., pre-encounter; immersion-emersion, and internalization) that are subdivided into eight identity types. 


\section{Pre-Encounter Exemplar}

There are three pre-encounter identity types; all types share the belief that "White is right," along with some level of disengagement (i.e., low salience) from their social or racial group identity as an African American. Thus, when accused of acting White, this African American may feel complimented rather than offended.

Assimilation. The assimilation type describes an African American whose social identity is organized around her or his sense of being an American and an individual (Cross \& Vandiver, 2001, p. 375). He or she places little salience on racial group affiliation and, consequently, is detached or distanced from the African American community and culture, even showing some disdain for Black culture. His or her primary identity is being an American-without qualification and without apology. One belief is that "We are in America, so get over the past."

Miseducation. This identity type is representative of an African American who accepts, unquestionably, the negative images, stereotypes, and historical misinformation about African Americans (Cross \& Vandiver, 2001). He or she sees little strength and few positives in the Black community, hesitates to engage in solving or resolving social injustices, and psychologically and physically distances him- or herself from the African American community. According to theory, this individual tends to compartmentalize his or her stereotypes so that such negative group images do not affect his or her personal selfimage. Thus, this person often is likely to hold the attitude "That's the way they act, but $I$ am different" (p. 376).

Racial self-hatred. In this third pre-encounter type, the individual experiences profoundly negative feelings and severe self-loathing about being African American. The dislike is internal, unhealthy, and the individual may resort to all sorts of tactics (including surgery) to modify physical features. Being African American may even be viewed as being cursed.

Movement from any one of the pre-encounter types comes from experiencing encounters, called conversion experiences. Sue and colleagues (2007) also termed these experiences as microaggressions-racial insults and offenses. Sue and colleagues provided nine cogent examples of microaggressions that potently remind African 
Americans that they may be viewed by other groups as inferior. These insults can be direct or indirect, and small (so to speak) or large. Examples include being told that "you speak well," having your academic credentials questioned, being questioned about your ability to purchase an expensive item, watching an African American on television being abused and/or beaten by police, being told by a teacher that you cheated on an assignment because it was so well done, being punished for an incident in which a White student was not, and so much more.

\section{Immersion-Emersion Exemplar}

This identity exemplar is characterized by two identity types, associated with a form of anti-White sentiment or extreme/militant proBlackness. There is a high degree of racial engagement. This is the antithesis of the pre-encounter exemplar. Thus, when accused of acting White, both types may have responses that range from feeling slighted to angry to enraged. To stop being accused of acting White, he or she may stop displaying the characteristic(s) associated with the accusation (e.g., dress or talk differently, disengage from academics, downplay intelligence).

Anti-white. The African American who holds anti-White sentiments is nearly consumed by a hatred of White people (Cross \& Vandiver, 2001), and all that Whiteness represents, such as privilege, power, and prestige. He or she is frequently full of fury and pent-up rage associated with social injustices (Cross \& Vandiver, 2001); rather than taking on the role of victim, the individual may victimize those viewed as the oppressor. Within the school context, there is a dislike of having White teachers and administrators, disdain for learning about White Americans, and a refusal to take directions from Whites, especially those in positions of authority.

Intense African American involvement. This individual often holds a simplistic, romanticized, and obsessive dedication to all things Black (Cross \& Vandiver, 2001). He or she engages in "Blackness" in a hyper-vigilant and/or cult-like fashion. The individual, for myriad reasons, may exaggerate or distort his or her sense of what is means to be African American. 


\section{Internalization Exemplar}

The internalization exemplar is comprised of three identity types. The underlying characteristic among them is high racial salience or engagement, and a sense of wholeness or peace. There is also a keen sense of social justice, equality, and equity. This individual is not likely to succumb to accusations of acting White; it has little to no effect on his or her psyche and performance.

Internalization nationalist. Here, the individual emphasizes an Afrocentric perspective about him- or herself, other African Americans, and the world. This individual proactively and assertively engages in and contributes to the African American community, endeavoring to decrease social injustices facing African Americans.

Internalization biculturalist. This identity type represents an African American who gives equal importance and salience to being an African American and an American. He or she celebrates being both, and engages positively in both cultures-without identity conflicts, doubt, and self-questioning.

Internalization multiculturalist. This type represents the prototype of an African American whose identity merges three or more social categories or frames of reference. He or she is interested in resolving issues that address multiple oppressions, and is confident and comfortable in multiple groups and settings. Racial salience and pride as an African American are positive in all settings.

To reiterate, when nigrescence theory is applied to the study of Black identity change, the three major exemplars or orientations (preencounter, immersion-emersion, and internalization) are viewed as stages. However, when the focus is on the socialization experiences, covering infancy through early adulthood, then the exemplars are viewed as bounded and fairly stable identity or reference group orientations (Cross \& Vandiver, 2001, p. 375). From a developmental perspective, a final point is that individuals will periodically pass in and out of certain nigrescence stages (p. 378), which is not to be interpreted as confusion or being unstable. Rather, such individuals are experiencing "recycling" to lifespan challenges that, ideally, will result in a deeper understanding and appreciation of one's Blackness. Recycling strengthens and enriches whatever identity type is in question. 
Several qualifications are necessary at this point. First, we must consider that African Americans in predominantly White settings (like gifted and AP classes) may experience more negative racial encounters or identity conversion experiences than those in predominantly African American settings (Ford, 1992; Ford et al., 2008a, 2008b; Smith, 1989). Secondly, African Americans in predominantly White settings also may experience such encounters at an earlier age than African Americans in predominantly Black settings. Third, because of characteristics often associated with giftedness (e.g., insightfulness, intuitiveness, sensitivity, keen sense of justice), gifted Black students may be particularly aware of and sensitive to racial injustices (encounters and microaggressions). Finally, one's stage of racial identity may be related to achievement (Ford, 1996). Specifically, there may be a curvilinear relationship between racial identity and achievement, with pre-encounter types (or stages) and internalization-commitment types/stages having the highest achievement orientation and being less vulnerable to peer pressures. Relatedly, the extent to which the individual is perceived as acting White or "selling out" and how he or she responds to the accusations are likely to be different. Pre-encounter individuals, because of their low racial engagement and salience or anti-Black attitudes, are likely to be rejected by some members of the African American community; conversely, immersion-emersion and commitment individuals, because of their engaged racial identity and salience, bicultural stance, and pluralistic perspectives, seem more likely to be accepted by members of the African American community. Immersion-emersion types appear so subsumed with finding and validating their social identity that academic achievement may have low significance in their livesthe need for affiliation may be stronger than the need for achievement (Whiting, 2006a, 2006b).

It is our experience and belief that African Americans encounter more barriers to racial identity engagement and development than White students (Helms, 1985; Parham, 1989; Parham \& Helms, 1985; Smith, 1989; Spencer \& Markstrom-Adams, 1990). Moreover, gifted African American students may experience more psychological and emotional problems than African American students not identified as gifted (Colangelo \& Exum, 1979; Exum, 1979; Exum \& Colangelo, 1981; Ford, 1996). In some situations, gifted or 
high-achieving minority students may perceive academic achievement as a pyrrhic victory (Fordham, 1988; Ogbu, 2003). They win in one respect-academically_but lose in other respects-socially, affectively, and/or psychologically. Feelings of loneliness, isolation, and rejection increase, and the need for affiliation begins to outweigh the need for achievement (Ford, 1996; Whiting, 2006a, 2006b). When caught in this psychological and social-emotional conflict, some Black students attempt to sabotage their achievement (e.g., procrastinating, failing to do assignments, exerting little effort, refusing to be in gifted education and advanced-level classes; Ford, 1996; Ogbu, 2003; Ogbu \& Simmons, 1998). Their interests and priorities change, with energy devoted to seeking and securing social acceptance or approval. Because of the numerous and complex problems that influence the social and psychological well-being of African American students, and because of our limited understanding of these problems, attention to racial identity and its development is vital in gifted education.

\section{Gender Considerations}

Given the earlier discussion in which data indicated that Black males, even when identified as gifted, succumb to peer pressures, it is also worth considering if and how racial identity differs between Black males and females. In our search for research and theories examining differences and similarities in racial identity between African American males and females, we found a disturbing trend. Although researchers have studied racial identity among Black females, this is not the case with Black males; instead, the preponderance of studies focus on gender identity-notions of masculinity—among Black males. Thus, we have more data on how African American males view themselves as males rather than as racial beings.

Cokley (2001) studied gender differences in racial identity among Black college students. Findings revealed that gender is an important demographic characteristic to consider when examining the psychosocial development of African American students. Results suggested that African American females in this sample were generally more motivated about being in college than African American male students. However, a different picture emerged with Black males. For them, racial identity was not related to their academic self-concept 
and academic motivation. Further, for Black males, racial identity had an inverse relationship with intrinsic motivation. This was the opposite of what is happening with Black females. As Cokley explained, one possible explanation for this trend is that, as Black males become increasingly disenchanted and disengaged from the educational process, their racial identity becomes detached from academics and increasingly associated with activities where there are more Black male role models and perceived opportunities for success (i.e., athletics). Stated another way, some African American males cope with social injustices by finding their identity, strength, and affirmation outside of school settings; if they do not perform well academically, there is little loss of worth and dignity.

\section{Discussion and Recommendations}

Although conceptual, theoretical , and data-based scholarship has been informative, limited scholarship has examined the racial identities of students who are gifted and African American; and gender considerations have been all but ignored. To effectively recruit and retain African Americans in gifted education, prevention and intervention efforts must be proactive and intentional and culture specific. The following section presents an overview of key recommendations, including multicultural counseling, multicultural education, mentoring, and educator training.

\section{Multicultural Counseling}

African American students experiencing peer pressures and racial identity difficulties can benefit from multicultural counseling. They need opportunities to share their concerns with other students who have had similar experiences. Who can gifted Black students turn to for emotional, psychological, social, and academic support? How do they feel about being identified and placed in gifted education and AP classes? How do they make friends with White students and those whose backgrounds are different from their own? How do Black males and females cope with negative peer pressures from other 
African American students? How do they cope with social injustices in school and other settings?

Sessions can focus on topics such as coping with peer pressures, conflict resolution strategies, anger management strategies, and understanding the stages of racial identity (see Ford, 1995, 1996). Table 1 presents some intervention strategies-supportive, intrinsic, and remedial strategies-for use when working with African American students. These strategies provide students with the support they need to feel confident in their abilities, to feel motivated, and to cope with barriers or roadblocks (internal, social, and academic). Specifically, intrinsic strategies augment African American students' belief in their ability (and right) to succeed in gifted education classes; supportive strategies help them to understand the benefits of participating in gifted education and AP classes; and remedial strategies help students to improve their academic performance, engagement, self-efficacy, and work ethic (Whiting, 2006a, 2006b).

Racial identity development focus. Psychological and counseling strategies and initiatives must help gifted African American students with poor or weak racial identities (i.e., being in the preencounter and immersion-emersion stages of identity) to understand and appreciate their dual identities of being both gifted and Black. White educational professionals must also recognize that Black students in the encounter and immersion-emersion stages of racial identity may both resent and reject their help. These students may generalize negative perceptions of Whites in general to White educators. Educators will need to be patient and persistent in gaining Black students' trust, especially if the students have faced discrimination.

Mentors and role model focus. A mentor and role model may be helpful in advancing African American students in the pre-encounter and immersion-emersion stages into healthier stages of racial identity. A mentor and role model can also help gifted Black students in the higher racial identity stages to maintain their positive self-image (Grantham, 2004a, 2004b; Whiting, 2006a, 2006b). Mentors and role models can guide gifted African American students in several ways. Mentors can talk with them about the short- and long-term advantages of being in gifted programs, while not negating possible disadvantages. The key here is to increase students' sense of empowerment and self-appreciation. Ideally, discussions will also be with 
Table 1

Prevention and Intervention Strategies With Multicultural
Counseling Focus

\begin{tabular}{|c|c|c|}
\hline Category & Goal/objective & Recommended strategies \\
\hline Intrinsic strategies & $\begin{array}{l}\text { To help gifted African } \\
\text { American students } \\
\text { to understand } \\
\text { the benefits of } \\
\text { participating in } \\
\text { gifted education } \\
\text { classes }\end{array}$ & $\begin{array}{l}\text { - Positive reinforcement, with } \\
\text { constructive and consistent } \\
\text { feedback } \\
\text { - Personally meaningful and } \\
\text { culturally relevant curriculum } \\
\text { - Multicultural or culturally } \\
\text { responsive education } \\
\text { - Mentors and role models } \\
\text { - Bibliotherapy and biographies } \\
\text { about resilient African Americans } \\
\text { as central characters; those who } \\
\text { faced and coped effectively with } \\
\text { social issues }\end{array}$ \\
\hline $\begin{array}{l}\text { Supportive } \\
\text { strategies }\end{array}$ & $\begin{array}{l}\text { To affirm gifted } \\
\text { Black students' belief } \\
\text { in their ability to } \\
\text { succeed in gifted } \\
\text { education classes }\end{array}$ & $\begin{array}{l}\text { - Conflict resolution skills and } \\
\text { anger management skills to cope } \\
\text { with peer pressures and other } \\
\text { social pressures } \\
\text { - Weekly or monthly opportunities } \\
\text { to meet with counselors and/ } \\
\text { or teachers to discuss personal, } \\
\text { social, and academic concerns } \\
\text { - Group counseling with other } \\
\text { gifted Black students } \\
\text { - Affective and student-centered } \\
\text { classrooms } \\
\text { - High teacher expectations } \\
\text { - Mentors and role models }\end{array}$ \\
\hline $\begin{array}{l}\text { Remedial } \\
\text { strategies }\end{array}$ & $\begin{array}{l}\text { To improve gifted } \\
\text { African American } \\
\text { students' academic } \\
\text { performance, } \\
\text { engagement, and } \\
\text { work ethic in the } \\
\text { specific area or areas } \\
\text { of difficulty }\end{array}$ & $\begin{array}{l}\text { - Academic counseling (e.g., } \\
\text { tutoring, study skills, test-taking } \\
\text { skills) } \\
\text { - Small-group instruction } \\
\text { - Test-taking skills training } \\
\text { - Accommodation of learning } \\
\text { styles and teaching styles }\end{array}$ \\
\hline
\end{tabular}

Note. Adapted from Ford (1996) and Grantham and Ford (2003). 
mentors and/or with African American adults who were successful students in gifted programs and their career.

\section{Multicultural Education}

School personnel must also (re)evaluate the extent to which their curriculum and instruction hinder or advance African American students' racial identities (Ford \& Harris, 1999). How does the curriculum promote negative and positive images of African American males and females? Does the curriculum (e.g., topics, posters, dolls, videos, and books) promote racial pride in gifted Black males and females? Is the classroom a socially and psychologically safe place for gifted Black students? For example, are Black males expected and allowed to be intelligent and studious? Do teachers effectively manage peer pressures?

Ford and Harris (1999) and Ford and Milner (2006) acknowledged the importance of ensuring that gifted students are exposed to high levels of multicultural content, as proposed by Banks and Banks (1995, 2006), while simultaneously ensuring that such work is challenging and promotes critical thinking and problem solving (Bloom, 1985). They also stressed the importance of using literature in which gifted Black males and females are central characters to help promote and nurture positive racial identity development.

\section{Multicultural Training for Educators}

To work successfully with gifted students, teachers must have formal preparation in gifted education. Likewise, to work effectively with African American students, school personnel require ongoing and extensive multicultural training (e.g., Banks, 2006). Such preparation increases our knowledge, dispositions, and skills at creating culturally responsive classrooms. With multicultural training, educators work against being colorblind or cultureblind (Ford, Moore, \& Milner, 2005); they recognize that students are culturally different, and that culture does matter in assessment, teaching, and learning (Banks, 2006; Banks \& Banks, 2006; Ladson-Billings, 1994; Shade, Kelly, \& Oberg, 1997). Relevant topics include: understanding culture and cultural diversity; decreasing stereotypes about African American 
students; understanding the impact of culture on test performance; creating culturally responsive classrooms; modifying instructional styles to match learning styles; and building relationships with students from diverse backgrounds.

\section{Gender Considerations}

More research is needed to better understand racial identity among Black males and females, as well as those identified as gifted. A serious void exists in the literature on these topics. Nonetheless, we have data indicating that efforts to nurture racial identity and pride among African American students must be systemic and systematic. When working with Black males, more intense and deliberate efforts may be required, for reasons previously explained. As early as possible, initiatives should expose Black males to other males who have been resilient and who have healthy racial identities (Grantham, 2004a, 2004b). For example, African American males need guidance in being critical consumers of the media so that they do not adopt negative images of themselves as learners; so that they are able to envision life outside of sports and entertainment (Whiting, 2006a, 2006b, in press). Educators will also need formal preparation that assists in decreasing stereotypes about Black males. Such training will facilitate their work in building relationships, raising expectations, and seeing strengths in this student population.

\section{Conclusions}

African Americans live in a world and learn in schools that seldom affirm their dignity and worth as racial beings. Many struggle to develop a positive sense of self, which includes views about their personal worth, their academic worth, and their social worth as racial beings. These destructive messages and associated challenges may be particularly difficult for African American students who are gifted. Black males find themselves in double jeopardy as they are most often confronted with negative images of themselves, especially in the media. These students frequently face negative peer pressures when doing well in school-they are often accused of acting White. When 
African American students develop healthy, positive, and/or engaged racial identities (namely, the internalization and internalization-commitment stages; Cross \& Vandiver, 2001), they are freer, more empowered, to focus on the need to achieve (Whiting, 2006a, 2006b). When gifted African American males and females develop positive, healthy, and/or engaged racial identities, they are less likely to succumb to negative peer pressures and social injustices.

Perceptions of self (self-esteem, self-concept, and racial identity) are developed over time, through interactions with others (children and adults), school curriculum, reading and literature, and the media. Likewise, racial identities are not formed in one setting; they are formed at home, by the media, in daycares, and in school. Racial identity is also dynamic; it can change. Thus, educators must proactively and aggressively endeavor to understand the powerful influence that racial identity has on African American students' achievement. To in any way trivialize this part of Black students' identity and social self is to deny them the opportunity to be all they can be.

\section{References}

Allen, R. L., Dawson, M. C., \& Brown, R. E. (1989). A schema-based approach to modeling an African American racial belief system. American Political Science Review, 83, 421-441.

Banks, J. A. (2006). Cultural diversity in American education. Boston, MA: Allyn \& Bacon.

Banks, J. A., \& Banks, C. A. M. (Eds.). (1995). Handbook of research on multicultural education. New York, NY: Simon \& Schuster Macmillan.

Banks, J. A., \& Banks, C. M. (Eds.). (2006). Multicultural education: Issues and perspectives (6th ed.). Hoboken, NJ: John Wiley \& Sons. Bloom, B. (Ed.). (1985). Developing talent in young people. New York, NY: Ballantine.

Brown, B. B., \& Steinberg, L. (1990). Academic achievement and social acceptance: Skirting the "brain-nerd" connection. Education Digest, 55(7), 55-60. 
Clark, K. B., \& Clark, M. K. (1940). Skin color as a factor in racial identification of Negro preschool children. Journal of Social Psychology, 11, 159-169.

Cokley, K. O. (2001). Gender differences among African American students in the impact of racial identity on academic psychosocial development. Journal of College Student Development, 42, 480-487.

Colangelo, N., \& Exum, H. A. (1979). Educating the culturally diverse gifted: Implications for teachers, counselors, and parents. Gifted Child Today, 6, 22-23, 54-55.

College Board. (2008). The 4th annual AP report to the nation. Washington, DC: Author.

Cross, W. E., Jr. (1971, July). Toward a psychology of Black liberation: The Negro-to-Black conversion experience. Black World, 13-27. Cross, W. E., Jr. (1995). The psychology of nigrescence: Revising the Cross model. In J. G. Ponterotto, J. M. Casas, L. A. Suzuki, \& C. M. Alexander (Eds.), Handbook of multicultural counseling (pp. 93-122). Thousand Oaks, CA: Sage.

Cross, W. E., Jr., \& Vandiver, B. J. (2001). Nigrescence theory and measurement: Introducing the Cross Racial Identity Scale (CRIS). In J. G. Ponterotto, J. M. Casas, L. A. Suzuki, \& C. M. Alexander (Eds.), Handbook of multicultural counseling (2nd ed.; pp. 371-393). Thousand Oaks, CA: Sage.

Exum, H. A. (1979). Facilitating psychological and emotional development of gifted Black students. In N. Colangelo \& R. T. Zaffran (Eds.), New voices in counseling the gifted (pp. 304-334). Dubuque, IA: Kendall/Hunt.

Exum, H. A., \& Colangelo, N. (1981). Culturally diverse gifted: The need for ethnic identity development. Roeper Review, 3, 15-17.

Feagin, J., \& Sikes, M. P. (1994). Living with racism: The Black middleclass experience. Boston, MA: Beacon Press.

Ford, D. Y. (1992). Determinants of underachievement as perceived by gifted, above-average, and average Black students. Roeper Review, 14, 130-136.

Ford, D. Y. (1994). The recruitment and retention of Black students in gifted programs. Storrs: University of Connecticut, The National Research Center on the Gifted and Talented. 
Ford, D. Y. (1995). A study of achievement and underachievement among gifted, potentially gifted, and average African American students. Storrs: University of Connecticut, The National Research on the Gifted and Talented.

Ford, D. Y. (1996). Reversing underachievement among gifted Black students: Promising practices and programs. New York, NY: Teachers College Press.

Ford, D. Y. (1998). The underrepresentation of minority students in gifted education: Problems and promises in recruitment and retention. Journal of Special Education, 32, 4-14.

Ford, D. Y. (2004). Intelligence testing and cultural diversity: Concerns, cautions, and considerations. Storrs: University of Connecticut, The National Research Center on the Gifted and Talented.

Ford, D. Y., \& Frazier Trotman, M. (2001). Teachers of gifted students: Suggested multicultural characteristics and competencies. Roeper Review, 23, 235-239.

Ford, D. Y., Grantham, T. C., \& Whiting, G. W. (2008a). Culturally and linguistically diverse students in gifted education: Recruitment and retention issues. Exceptional Children, 74, 289-308.

Ford, D. Y., Grantham, T. C., \& Whiting, G. W. (2008b). Another look at the achievement gap: Learning from the experiences of gifted Black students. Urban Education, 43, 216-239.

Ford, D. Y., \& Harris, J. J., III. (1996). Perceptions and attitudes of Black students toward school, achievement, and other educational variables. Child Development, 67, 1141-1152.

Ford, D. Y., \& Harris, J. J., III. (1999). Multicultural gifted education. New York, NY: Teachers College Press.

Ford, D. Y., Harris, J. J., III, \& Schuerger, J. M. (1993). Racial identity development among gifted Black students: Counseling issues and concerns. Journal of Counseling and Development, 71(4), 409-417.

Ford, D. Y., \& Milner, H. R. (2006). Counseling high achieving African Americans. In C. C. Lee (Ed.), Multicultural issues in counseling: New approaches to diversity (pp. 63-78). Alexandria, VA: American Counseling Association. 
Ford, D. Y., Moore, J. L., III, \& Milner, H. R. (2005). Beyond cultureblindness: A model of culture with implications for gifted education. Roeper Review, 27, 97-103.

Fordham, S. (1988). Racelessness as a factor in Black students' school success: Pragmatic strategy or pyrrhic victory? Harvard Educational Review, 58(1), 54-84.

Fordham, S. (1991). Peer-proofing academic competition among Black adolescents: "Acting White" Black American style. In C. E. Sleeter (Ed.), Empowerment through multicultural education (pp. 69-93). Albany: State University of New York Press.

Fordham, S. (1996). Blacked out: Dilemmas of race, identity, and success at Capital High. Chicago, IL: The University of Chicago Press.

Fordham, S., \& Ogbu, J. U. (1986). Black students' school success: Coping with the "burden of 'acting White." The Urban Review, 18, 176-203.

Fryer, R. G., Jr., \& Torelli, P. (2006). An empirical analysis of "acting White." Retrieved from http://econweb.fas.harvard.edu/faculty/ fryer/papers/fryer_torelli.pdf

Grantham, T. C. (2004a). Multicultural mentoring to increase Black male representation in gifted programs. Gifted Child Quarterly, $48,232-245$.

Grantham, T. C. (2004b). Rocky Jones: Case study of a high-achieving Black male's motivation to participate in gifted classes. Roeper Review, 26, 208-215.

Grantham, T. C., \& Ford, D. Y. (2003). Beyond self-concept and selfesteem for African American students: Improving racial identity improves achievement. High School Journal, 87, 18-29.

Harmon, D. (2002). They won't teach me: The voices of gifted African American inner-city students. Roeper Review, 24, 68-75.

Helms, J. (1985). Toward a theoretical explanation of the effects of race on counseling: A Black and White model. The Counseling Psychologist, 12, 153-165.

Ladson-Billings, G. (1994). Who will teach our children: Preparing teachers to successfully teach African American students. In E. R. Hollins, J. E. King, \& W. C. Hayman (Eds.), Teaching diverse populations: Formulating a knowledge base (pp. 129-158). New York: State University of New York Press. 
Louie, J. (2005). We don't feel welcome here: African Americans and Hispanics in Metro. Cambridge, MA: The Civil Rights Project at Harvard University.

Luftig, R. L., \& Nichols, M. L. (1989). Assessing the perceived loneliness and self-concept functioning of gifted students in self-contained and integrated settings. Unpublished manuscript, Miami University, Department of Educational Psychology, Oxford, OH.

McArdle, C. G., \& Young, N. F. (1970). Classroom discussion of racial identity or how can we make it without "acting White"? American Journal of Orthopsychiatry, 40, 135-141.

Moore, J., III, Ford, D. Y., \& Milner, E. (2005). Recruitment is not enough: Retaining African American students in gifted education. Gifted Child Quarterly, 49, 51-67.

Ogbu, J. U. (2003). Black students in an affluent suburb: A study of academic disengagement. New York, NY: Lawrence Erlbaum.

Ogbu, J. U., \& Simmons, H. D. (1998). Voluntary and involuntary minorities: A cultural-ecological theory of school performance with some implications for education. Anthropology and Education Quarterly, 29, 155-188.

Oyserman, D., Gant, L., \& Ager, J. (1995). A socially contextualized model of African American identity: Possible selves and school persistence. Journal of Personality and Social Psychology, 69, 1216-1232.

Parham, T. A. (1989). Cycles of psychological nigrescence. The Counseling Psychologist, 17, 187-226.

Parham, T. A., \& Helms, J. E. (1985). Relation of racial identity attitudes to self-actualization and affective states of Black students. Journal of Counseling Psychology, 32, 431-440.

Phinney, J. S. (1990). Ethnic identity in adolescents and adults: Review of research. Psychological Bulletin, 108, 499-514.

Shade, B. J., Kelly, C., \& Oberg, M. (1997). Creating culturally responsive classrooms. Washington, DC: American Psychological Association.

Smith, E. M. J. (1989). Black racial identity development. The Counseling Psychologist, 17, 277-288.

Spencer, M. B., \& Markstrom-Adams, C. (1990). Identity processes among racial and ethnic children in America. Child Development, $61,290-310$. 
Sue, D. W., Capodilupo, C. M., Torino, G, C., Bucceri, J. M., Holder, A. M. B., Nadal, K. L., \& Esquilin, M. (2007). Racial microagressions in everyday life: Implications for clinical practice. American Psychologist, 62(4), 271-286.

Upchurch, C. (1997). Convicted in the womb: One man's journey from prisoner to peacemaker. New York, NY: Bantam.

U.S. Department of Education. (2006). Elementary and Secondary Civil Rights Survey. Washington, DC: Author. Retrieved from http://www2.ed.gov/about/offices/list/ocr/whatsnew.html

Whiting, G. W. (2006a). Enhancing culturally diverse males' scholar identity: Suggestions for educators of gifted students. Gifted Child Today, 39(3), 46-50.

Whiting, G. W. (2006b). From at risk to at promise: Developing a scholar identity among Black male adolescents. Journal of Secondary Gifted Education, 17, 222-229.

Whiting, G. W. (in press). Overrepresentation of African American males in special education. Lansing: Eastern Michigan University. 